\title{
Twenty Nile Rivers escape the Mediterranean Sea - a giant water vapor spill boosting the July 202 I floods in Western Europe
}

\begin{abstract}
In summer 2021, severe drought and heat waves hit the Western United States, Canada, and many other areas around the world. At the same time, record-breaking floods devastated Western Europe (WE) and Central China. Drought and flooding are a water imbalance problem, and heat waves are always coupled with drought or originate from hot, arid areas. Global average evaporation and precipitation are balanced and steady. When some areas receive less precipitation, other areas receive more, often as heavy downpours. This study analyses one particular freshwater imbalance area - the Mediterranean Basin (MB), from a historical view and of recent trends. The net water vapor output from MB is equivalent to about 20 times the Nile River discharge. The north-south seesaw precipitation trends across Europe clearly indicate a water vapor transfer from MB to Western and Northern Europe. An upper low-pressure system and abundant water vapor supply from MB are an ideal combination for lingering heavy downpours and floods over WE, such as the case in July 2021. The root cause of MB freshwater imbalance is identified as the Sahara expansion. The breach of the green Sahara about 5700 years ago was the desiccation of the Atlas Basin. Based on water cycle stability a solution is suggested to restore the Sahara back to green.
\end{abstract}

Keywords: flood, freshwater imbalance, freshwater deficit, drought, downpour, heat wave, Mediterranean Basin, the Sahara, water cycle
Volume 5 Issue 4 - 202I

\author{
Hong-Quan ZHANG \\ Williams Chair Professor of McDougall School of Petroleum \\ Engineering, The University of Tulsa, USA
}

Correspondence: Hong-Quan ZHANG,Williams Chair Professor of McDougall School of Petroleum Engineering, The University of Tulsa, OK, USA, Email hong-quan-zhang@utulsa.edu

Received: August 02, 2021 | Published: August 18, 2021
Abbreviations: AB, Atlas Basin; BP, calendar year before 1950; DGDWGW, dry gets drier, wet gets wetter; $E-P$, evaporation minus precipitation, or freshwater deficit; GSP, the green Sahara period; MB, the Mediterranean Basin; mm, millimeter; MS, the Mediterranean Sea; NAWAM, North Africa, West Asia, and the Mediterranean; NE, Northern Europe; SST, sea surface temperature; WE, Western Europe; yr, year

\section{A water imbalance problem}

\section{Record drought and flooding in summer 202I}

Historic drought gripped most of the Western US during the first half of 2021 before record-breaking heat waves scorched the area and West Canada one after another. Then, wildfires ravaged many Western states still recovering from past blazes. In early July, downwind under the same westerly jet-stream and across the Atlantic Ocean, devastating floods overwhelmed western Germany, parts of Belgium and the Netherlands. Precipitation records were smashed across a wide area of the Rhine basin and in northwest Europe. A usual month's worth of July rain fell on London in a single day. Closely following the Western Europe (WE) deluge, China experienced similar intensive flooding in the downwind populous areas of its desertifying northwest provinces. A year's average rainfall poured onto Zhengzhou, the capital city of Henan Province, in three days. Further east, suburbs of Tokyo in Japan were drenched in the heaviest rainfall since measurements began. About the same time, cities in Libya, Kuwait, Pakistan, India, and many other countries have also endured unusually high temperatures. Then, many Mediterranean countries were afflicted by the worst wildfires in decades. Events that were once in 100 years are becoming commonplace. Politicians and some climatologists are quick to attribute these extreme weather events to climate change without giving a clear mechanism. For example, with recent global warming, temperatures in the Arctic rise twice as fast as the global average, ${ }^{1}$ which means the temperature difference between tropics and the Arctic is smaller. Since the strength of heat and cold waves depends on temperature difference, a smaller difference should lead to weaker heat or cold waves. Then, why is the reality the opposite? Are we taking the effect as the cause?

Water is a powerful moderator for temperature extremes. When an area gets drier, cloud cover becomes thinner, precipitation drops, and less water is evaporated and transpired on the ground. The surface air gets hotter, and the day and night temperature difference becomes larger. Large temperature differences between dry and wet areas and between day and night are the drivers of heat or cold waves. The temperature increase in arid areas further reduces the local relative humidity and makes rainfall even more difficult, exacerbating the drought and heat waves. On the other hand, rainfall is a pulsive event after the loaded overcast penetrates the under-saturated air (which is like an insulating cushion) over the surface. It reduces the surface temperature and maintains the local relative humidity close to saturation, so that the incoming condensate in the clouds will pour to the ground easily. The strength and duration of the rainfall depend on the condensate supplies that originated from the evapotranspiration in upwind and neighboring areas. When massive moist air is circulated into a low-pressure system, heavy rainfall will pour into the area it penetrates and lingers, and floods occur if the drainage system is overwhelmed. 


\section{Dry gets drier, otherwise gets flooding}

During the last century, there have been three systematically drying areas in the world. The biggest drying area is North Africa, West Asia, and the Mediterranean (NAWAM) region. The second drying area is northwest China. The third drying area is the Western US, although the severity is less than the first and second areas. ${ }^{2}$ With most of the Earth's surface covered by seawater, the overall global water evaporation rate is steady. What goes up must come down. On average, every evaporated water molecule takes about 10 days to fall back onto the ground. When the arid areas receive less rainfall and become drier, some other areas must receive more precipitation. For example, this summer my city Tulsa, OK (located between the dry West and wet East) had more than usual downpours and mild temperature, when the West was experiencing severe drought and heat waves. The dry areas throughout the subtropics are becoming drier, and the wet areas in the tropic and high latitudes are becoming wetter. This "dry gets drier, wet gets wetter (DGDWGW)" phenomenon is clearly identified in a study using data from the NASA Gravity Recovery and Climate Experiment (GRACE) satellite mission to track trends in freshwater from 2002 to 2016 across the globe. ${ }^{3}$

There is more behind the recent DGDWGW trend. Downpour intensity is increasing in many wet areas and even in areas where total precipitation is decreasing such as northern Italy, Turkey, Yemen, Saudi Arabia, Oman, Iran, Pakistan, Afghanistan, India, north China (downwind of the drying Loess Plateau), and many others - "it never rains but it pours." In the humid eastern region of the US, studies found that 1", 2", and 3" downpours had increased $25 \%, 35 \%$ and $50 \%$, respectively from 1950 to $2018 .{ }^{4}$ Weather has become more violent. Observations indicate that what is happening is a water imbalance problem due to the deteriorating water cycle. ${ }^{12}$ Temperature rise is a feedback loop effect and may not be the root cause. This paper will examine the water cycle of the most unbalanced area in the world - the Mediterranean Basin (MB), to assess its contribution to the flooding in the neighboring areas, such as the deluge that devastated WE in July 2021.

\section{The Mediterranean water imbalance}

By nature, there are many uncertainties in stormy weather events which cause severe floods. However, for WE floods, one contributor is certain - the giant water vapor input from MB. A recent study shows an average freshwater deficit (evaporation minus precipitation, $E-P$ ) of about $2.4 \mathrm{~mm} /$ day in the Mediterranean Sea (MS)..$^{5}$ There is a significant east-west asymmetry ranging from $3.5 \mathrm{~mm} /$ day in the eastern part to about $1.1 \mathrm{~mm} /$ day in the western part of the basin. The zonal asymmetry in the water deficit is driven by evaporation differences that are in turn determined by variability in the air-sea humidity difference in the different parts of MS. Also, the freshwater deficit increased in the 1988-2005 period, due to increases in evaporation driven by increasing sea surface temperature (SST). MS has a water surface area of about 2.5 million $\mathrm{km}^{2}$ (965,000 sq mi). Accordingly, the annual water deficit for MS is about 2,190 billion $\mathrm{m}^{3}$. Part of this deficit is compensated by the runoff in MB as rivers flowing back to MS, but the majority is supplied by the inflows through the Strait of Gibraltar and the Turkish Straits of Bosphorus and Dardanelles as well as the Nile River. The Suez Canal contribution is minimal.

As shown in Figure 1, the inflow through the Strait of Gibraltar is about 1,200 billion $\mathrm{m}^{3} / \mathrm{yr}^{6}$ The flow from Black Sea to MS is about 250 billion $\mathrm{m}^{3} / \mathrm{yr}^{7}$ The Nile River discharge is about 80 billion $\mathrm{m}^{3} / \mathrm{yr}$. Therefore, the total water inflow to MB from outside is about 1,530 billion $\mathrm{m}^{3} / \mathrm{yr}$. All the other rivers within MB make up a runoff of about
660 billion $\mathrm{m}^{3} / \mathrm{yr}$ to meet the total deficit of 2,190 billion $\mathrm{m}^{3} / \mathrm{yr}$. The 660 billion $\mathrm{m}^{3} / \mathrm{yr}$ runoff is an internal circulation, but the 1,530 billion $\mathrm{m}^{3} / \mathrm{yr}$ surface input from outside must be transferred by atmospheric circulation as water vapor to outside to keep the water mass at steady state in MB. This gigantic water vapor overflow is about 20 times the Nile River annual discharge. In other words, about 20 Nile Rivers continuously escape MB as water vapor through the atmosphere. This is the biggest water vapor source in the world from a single basin except the oceans. It greatly contributes to the precipitation rate in the surrounding wet areas.

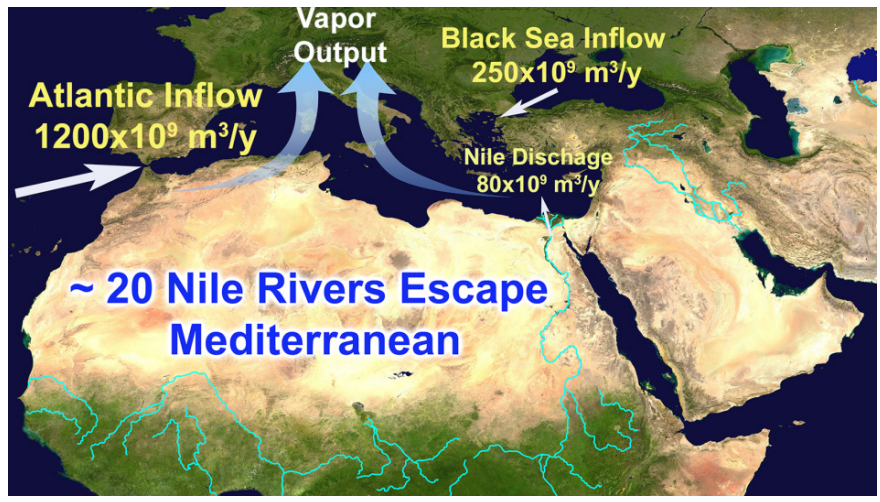

Figure I Water imbalance in the Mediterranean Basin.

Overall, the ocean receives $77 \%$ global precipitation $(P)$ and provides $85 \%$ global evaporation $(E)$. Global ocean precipitation is about $1033 \mathrm{~mm} / \mathrm{yr}$, and evaporation is about $1144 \mathrm{~mm} / \mathrm{yr}$. The 111 $\mathrm{mm} / \mathrm{yr}$ freshwater deficit $(E-P)$ is met by river flows from land to sea. ${ }^{8}$ As shown in Figure 2, the evaporation from MS is about $1276 \mathrm{~mm} /$ $\mathrm{yr}$, higher than the global ocean average. The precipitation of MS is about $400 \mathrm{~mm} / \mathrm{yr},{ }^{9}$ much lower than the global ocean average. The freshwater deficit of MS is about $876 \mathrm{~mm} / \mathrm{yr}^{5}{ }^{5}$ Compared to MS, the Red Sea has a much higher freshwater deficit of about $2060 \mathrm{~mm} / \mathrm{yr}^{10}$ Its water vapor output is equivalent to about 11 times the Nile River discharge. The Persian Gulf has a water deficit of about $1660 \mathrm{~mm} / \mathrm{yr} .{ }^{11}$ Its water vapor output is equivalent to about 5 times the Nile River discharge. The water vapor supply is abundant in the NAWAM region, but sadly the lion's share cannot fall locally to the dry surface due to the low relative humidity. Even worse, this giant water vapor output goes to neighboring wet areas and generates unwanted additional rainfalls. Nevertheless, the severe freshwater imbalance did not exist during the green Sahara period (GSP).

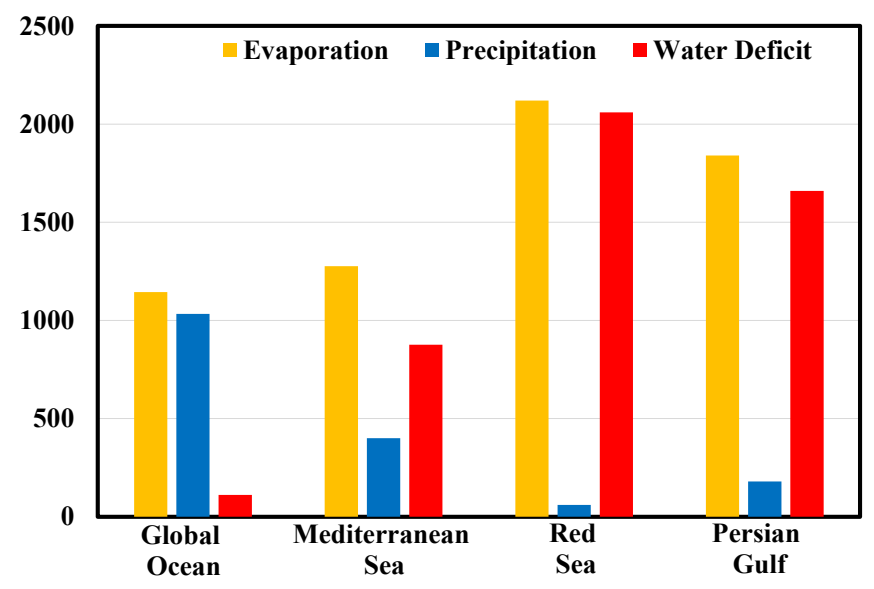

Figure 2 Freshwater deficit of the Mediterranean Sea compared to global ocean average (also Red Sea and Persian Gulf). 


\section{The Mediterranean water cycle changes during the Holocene}

\section{Six millennia now and then}

The Mediterranean aridification has been an ongoing process for almost six thousand years. The only dominant control of this process is the Sahara's formation. All the other fluctuations, such as the North Atlantic Oscillation (NAO), are short-term events which do not dictate the long-term trend. Figure 3 shows the NAWAM region today and during GSP, which lasted from about 12,000 to 5700 years ago. ${ }^{12}$ From this stark contrast, it is obvious that the climate change in the Mediterranean Basin (MB) is a direct effect of the Sahara's formation. During GSP, most MB landscapes were fundamentally different from those that have existed afterward in historical and modern times. ${ }^{13}$ The Mediterranean Sea (MS) freshwater deficit was certainly very small, similar to the global average, corresponding to a balanced evaporation and precipitation. The beginning and trend of aridification in MB were synchronous with the start and expansion of the Sahara. Protected by seawater evaporation, the Mediterranean lands would not reach the point of desertification like the Sahara. However, the scorching effect from the dry and hot Sahara has totally changed the MB climate.

\section{The winds from the south}

MB is in a transitional zone between the North African region dominated by subtropical high-pressure system, and central and Northern Europe (NE) where mid-latitude westerly circulation dominates. The westerly is the main jet stream over this area, and it moves south in the winter and north in the summer. It is not steady and swings up and down with the northern hemisphere's atmospheric circulation. When a low-pressure system (cyclone) moves into MB, southerly winds blow from the Sahara in advance of the system. For a high-pressure system (anticyclone), the hot southerly winds follow behind the system and strengthen heat waves, such as the anticyclone Lucifer which pushed the temperature in Sicily to a new record $48.8^{\circ} \mathrm{C}$ on August 11, 2021

The termination of the green Sahara and the following drying process directly affected the climate of MB, especially in the southern and eastern areas. Consequently, the southerlies received by MB are loaded with less and less water vapor often causing heat waves in the summer. This scorching effect of the ever-drying Sahara suppresses the MB precipitation to lower and lower levels. When the southerly winds reach the European coast, the air is again loaded with moisture and forms low Stratus clouds, leading to irregular heavy rains.

When a low-pressure system moves across West Europe (WE) in summer, it draws southerly winds from $\mathrm{MB}$, and the abundant water vapor from this area is transported to the north. As shown in Figure 4, a large upper-level low-pressure system loomed over WE in mid-July 2021, setting a perfect condition for the moist air from MB to flow north over the mountain ranges. The abundant water vapor supply from the hot MB played an important role exacerbating the deluge in WE.

\section{Rains skip hot summer}

The vegetation changes in the Adriatic Basin show that, during the mid-Holocene, the wet summers lead to permanent moisture all year around resulting in a homogeneous seasonal precipitation regime. ${ }^{14}$ After 6000 BP, summer precipitation decreases towards present-day values while winter precipitation rises regularly, showing the setting up of Mediterranean climate conditions. A high-resolution oxygen and carbon isotopic record in a speleothem from the eastern Mediterranean region shows a decrease of $\sim 400 \mathrm{~mm}$ in annual rainfall after the mid-
Holocene. ${ }^{15}$ The diatom record from Lago di Massaciuccoli (Tuscany, Italy) suggests freshwater conditions and rather high lake levels until c.6000 years ago. The subsequent shift towards brackish conditions peaked at around $5500 \mathrm{BP} .{ }^{16}$ This shift to a pervasive change towards a drier climate was consistent with elsewhere in the Mediterranean and Northern African regions but stands in contrast to the shift towards a cooler and more humid climate in the nearby Alps (200-350 km north) and in central Europe. Corresponding to the drying in the southern Mediterranean, there was a humid period between 5600$5300 \mathrm{BP}$ in the Alps. ${ }^{17}$ Paleoenvironmental and archaeological data from Arbon Bleiche, Lake Constance (Switzerland) give evidence of a rapid rise in lake-level dated by tree-ring and radiocarbon to 5320 BP. Many findings indicate a sharp seesaw transition between the Mediterranean and the Central European climatic sub-systems after the mid-Holocene. However, this contrast was not seen earlier, when central Europe experienced drier and more continental conditions than today. ${ }^{18}$ Precipitation has generally increased in northern and northwestern Europe but has generally decreased in southern Europe, separated by the Alps.

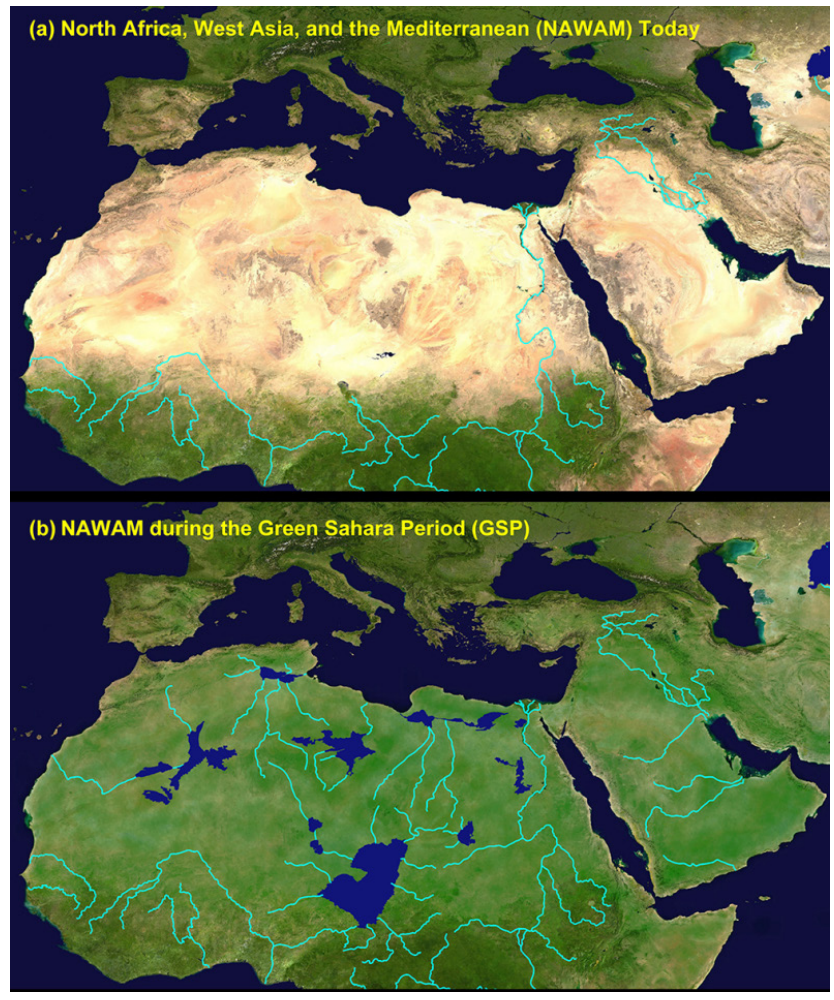

Figure 3 The NAWAM region (a) today and (b) during GSP.

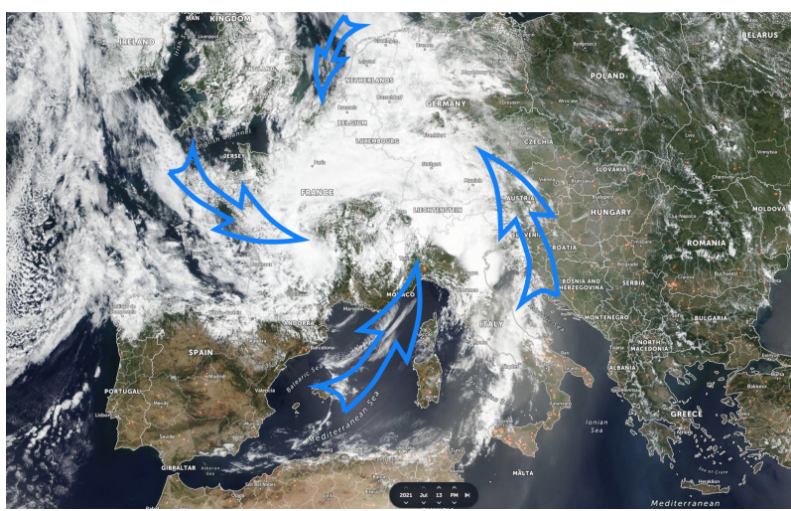

Figure 4 The upper low-pressure system inundated WE in July 2021 (from Zoom.Earth). 


\section{Trees grow evergreen}

Predominant or coexistent deciduous forest was distributed over almost all Mediterranean coastal and inland areas 6000 years ago. After 5000 BP, evergreen sclerophyllous taxa expanded and replaced the deciduous vegetation in many places of MB. ${ }^{19}$ This landscape transformation was directly related to the disappearance of summer rainfalls. At Pergusa in Sicily (the most southerly site) and at Malo Jezero in Dalmatia there was a switch from deciduous to evergreen oak dominance. A similar switch was also observed in western and southern Greece. Between approximately 8300 and 5400 BP, the Tiber delta area, Italy was covered by dense oak-dominated forests. An abrupt change around $5400 \mathrm{BP}$ marked the transition to an open landscape. ${ }^{20}$ Around 5000-4000 BP, the expansion of sclerophyllous vegetation observed in many southern European pollen records has been interpreted as being due to aridification, leading to the establishment of the modern Mediterranean climate between 2500 and 2000 BP. ${ }^{21}$ In the Villaverde region (southeast Spain), between about 6000 and 5300 BP, deciduous taxa were dominant while Pinus continued to regress. Subsequently, an aridification phase began. Deciduous broad-leaf trees regressed while sclerophyllous and evergreen species expanded. At Eski Acigöl, Turkey, deciduous oaks had a sharp decline around 4500-4000 BP. Along with the vegetation transition to evergreen due to the drying summer climate, fire activity also widely increased after $5000 \mathrm{BP}$ in $\mathrm{MB} .^{22}$ All the vegetation transitions from deciduous to evergreen in $\mathrm{MB}$ are consistent with the Sahara formation which started abruptly around 5700 years ago in the Atlas Basin and expanded gradually afterward. ${ }^{12}$

\section{Recent water cycle changes}

\section{Precipitation trends across the Mediterranean}

The seesaw climate trend has been accelerating during the last century, with $\mathrm{MB}$ becoming drier and $\mathrm{NE}$ becoming wetter. The Mediterranean Basin (MB) accumulates most of its annual precipitation via migratory storms during November-April. It had experienced 10 of the 12 driest winter seasons since 1902 in just the last 20 years before 2010. ${ }^{23}$ A change in wintertime Mediterranean precipitation toward drier conditions had occurred over 1902-2010. Figure 5 shows the mean annual precipitation changes from 1950 to 2010 in the west, central and east Mediterranean coastal areas, mostly on the north side. ${ }^{24}$ Clearly, precipitation has declined in all areas of the Mediterranean, with more decrease in the west than in the east.
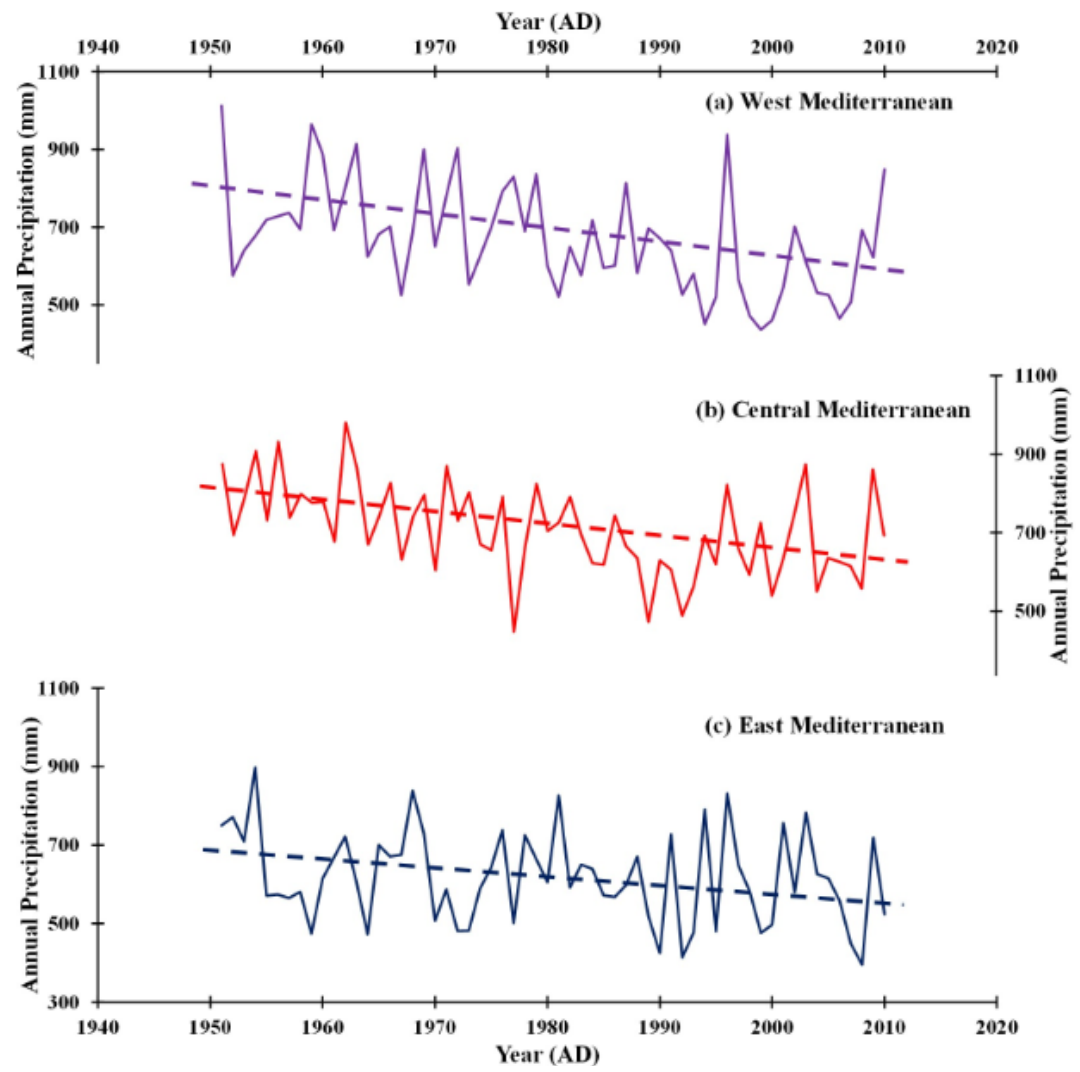

Figure 5 Mean annual precipitation in (a) west, (b) central, and (c) east Mediterranean. ${ }^{24}$

\section{Precipitation trends in the Sahara and West Asia}

Using data from the Climate Change Knowledge Portal on the World Bank Group's website, ${ }^{25}$ Figure 6 (a) and (b) show the annual precipitation changes from 1900 to 2016 in Egypt and Libya to represent the aridification trend in the Sahara. Clearly there is a declining trend on the already extremely low annual precipitation at the center of the Sahara. The air humidity in the Sahara has become lower than a century ago. Figure 6 (c) to (f) show the annual rainfall changes from 1900 to 2016 in Syria, Iraq, Israel, and Jordan. In all these countries overlapping the traditional Fertile Crescent, rainfall has decreased significantly during the last century, and the decline has especially accelerated since the 1980s. The synchronous decline of rainfall in North Africa, West Asia, and the Mediterranean (NAWAM) region during the late-Holocene and the last century proves that the climate of this entire area is dominated by the same water cycle system. The theme is the Sahara expansion and impact. 

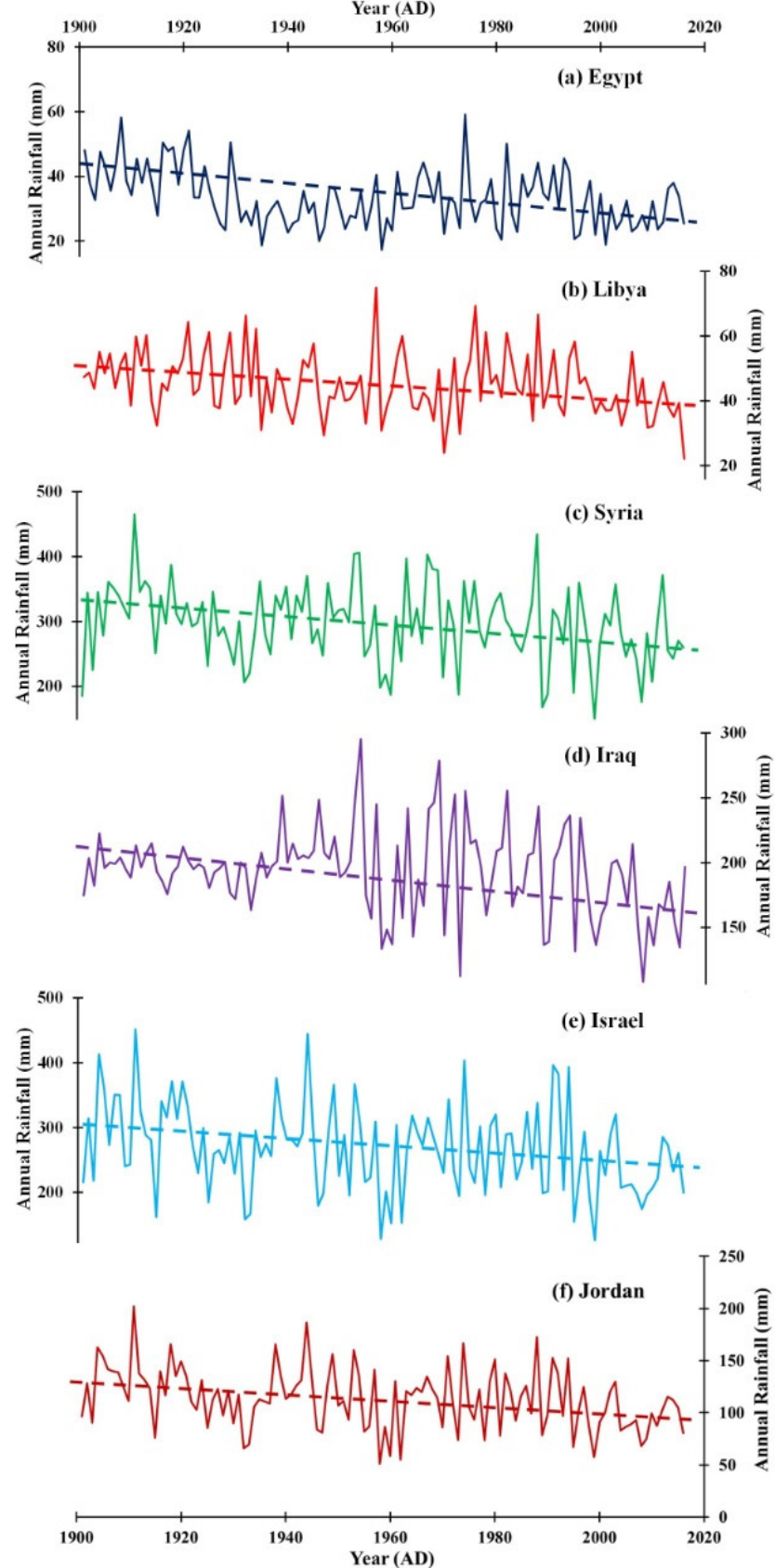

Figure 6 Annual rainfall changes in the Sahara and West Asia from 1900 to 2016: (a) Egypt, (b) Libya, (c) Syria, (d) Iraq, (e) Israel, (f) Jordan. ${ }^{25}$

\section{Where does the water vapor go?}

The net annual water vapor output from MB to the outside is estimated to be about 20 times the Nile River discharge rate. The aridity and precipitation decrease in the NAWAM region propel this huge water vapor output. Consequently, this output becomes input as additional rainfalls to other areas through atmospheric circulation. Generally, aridification and desertification in some areas make the global freshwater distribution more uneven, and floods become more frequent and severe. Then, where is the MB water vapor output destination? It must be the neighboring areas showing an upward precipitation trend. In Figure 7, data from the Climate Change Knowledge Portal are used again to show the annual rainfall changes from 1900 to 2016 in high-latitude northern countries. ${ }^{25}$ In Canada, the precipitation increase during the last century is about $8 \%$, the lowest compared with the other countries at the same latitude. Precipitation in Greenland increased about $20 \%$. The highest precipitation increase was recorded at Iceland at about $30 \%$. In Norway, the precipitation increase was about $25 \%$. Finland registered a precipitation increase of about $22 \%$, and Russia about $19 \%$.
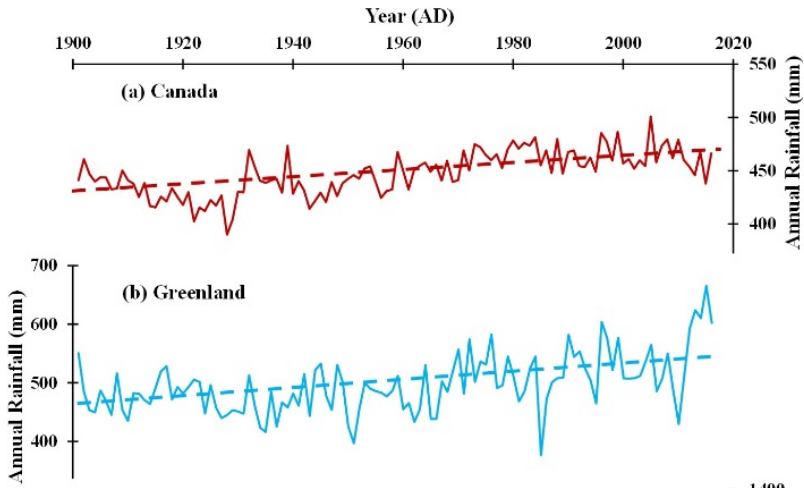

(c) Iceland

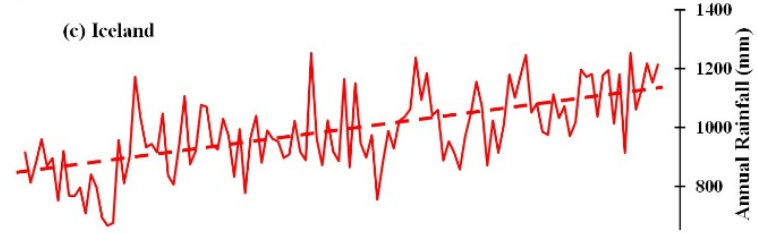

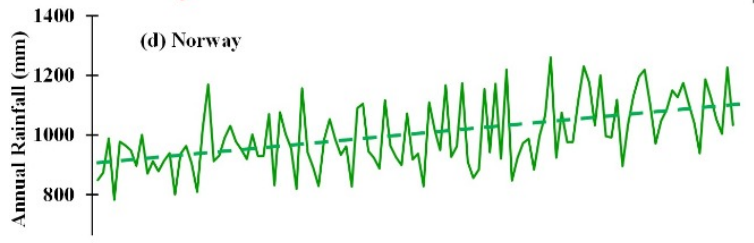

(e) Finland
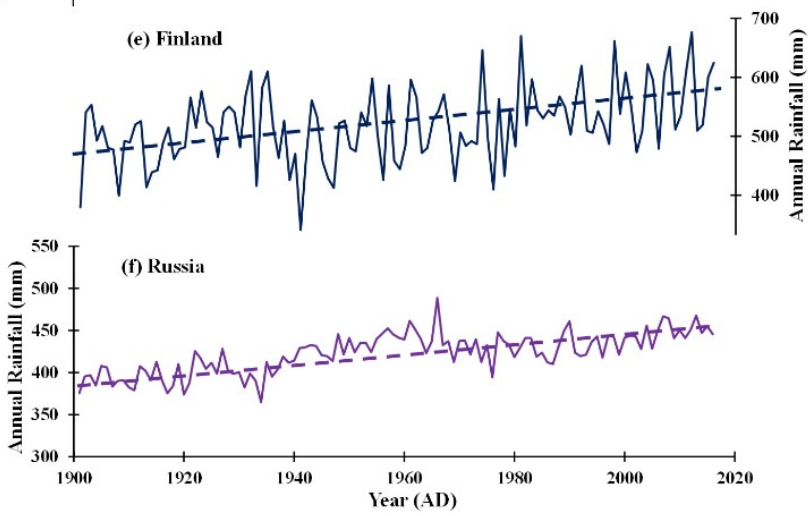

Figure 7 Annual rainfalls from 1900 to 2016 in high-latitude northern countries. ${ }^{25}$

The sea surface temperature (SST) increase in the North Atlantic Ocean generates slightly more vapor and contributes to the precipitation in the surrounding land areas. However, precipitation in downwind MB has not gone higher although the evaporation from MS has increased due to the rising SST. Instead, precipitation has declined considerably during the last century in MB. Obviously, the precipitation belonging to $\mathrm{MB}$ has gone north. The main contributor to the significant precipitation increases in NE is the rainfall decrease and water vapor output increase from $\mathrm{MB}$, an area undergoing systematic desiccation not only in the last century but also over the last six millennia. When the additional moisture is circulated to higher latitude areas, the low temperature and high relative humidity help 
offload it and increase the local precipitation. This is mainly a oneway transport process. When the jet stream swings back to hotter MB, its relative humidity becomes much lower and weakens precipitation.

\section{The broken water cycle and cure}

\section{MB water cycle then and now}

For any area, there is a relationship between the mean precipitation $(P)$ and the assumed mean evaporation (or evapotranspiration, $E$ ), under the same boundary conditions. We can use Figure 8 to illustrate this non-linear relationship between $P$ and $E$ which is postulated to increase from 0 to a high value. $P$ increases with $E$, first slowly and then rapidly. For a land area with favorable boundary conditions (e.g., global average), after the critical point 'A' is passed, $P$ will be higher than $E$, and there will be runoff surplus flowing out through rivers. If $P$ is kept at a level higher than $E$, the water cycle is stabilized, and the ecosystem is maintained at a healthy, 'affluent' condition. However, the critical point ' $\mathrm{A}$ ' is an unstable threshold. If $P$ drops below this value, $E$ will be higher than $P$, and the system will become "insolvent." ${ }^{12}$ The lower water evaporation will reduce the local relative humidity and further decrease $P$. The water cycle will get into a self-propelled destabilizing process, move away from point 'A', and finally stabilize at point ' $\mathrm{B}$ ', which corresponds to a desert condition.

For MS today, due to the hot and dry boundary conditions on the Sahara and West Asia sides, the precipitation is only about $400 \mathrm{~mm} /$ $\mathrm{yr}$ corresponding to an evaporation of about $1276 \mathrm{~mm} / \mathrm{yr}$. However, the boundary conditions were totally different during GSP. With all the surrounding areas in lush green, the MS freshwater deficit must be proportionally close to the global ocean average if not smaller. Assuming the same evaporation rate, the precipitation in this area would be around $1150 \mathrm{~mm} / \mathrm{yr}$ (see Figure 8). The majority of the water vapor would become precipitation and circulate inside MB instead of escaping outside. The water cycle was in balance. The seawater inflow through the Strait of Gibraltar must be very small, or even negative.

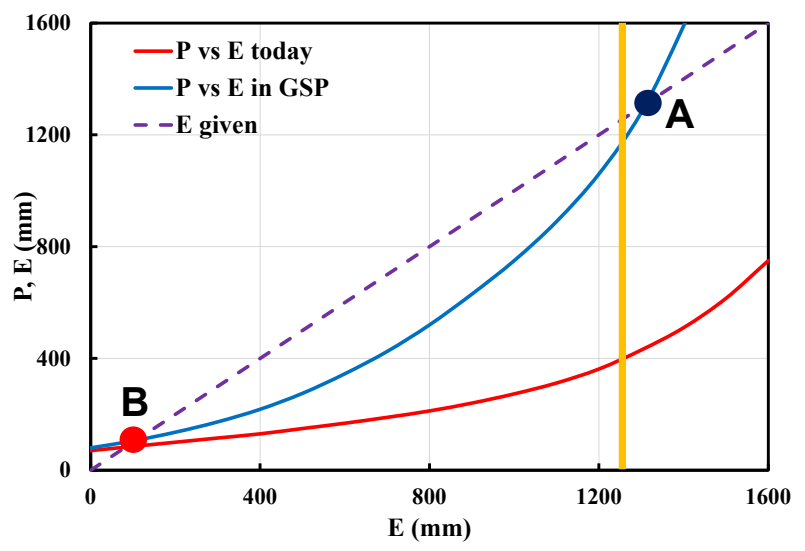

Figure 8 MS water cycle today and during GSP.

\section{The water cycle breach and cure}

Strong paleoclimate evidence indicates a lush green Sahara started around 12,000 years ago. ${ }^{26,27}$ The legendary Atlas Empire described by Plato and the inundated Atlantis were likely part of the green Sahara. ${ }^{28}$ About 5700 years ago, the green Sahara suddenly began to wither from the Atlas Basin, as shown in Figure 9. ${ }^{12}$ This is the rain shadow area of the Atlas Mountain range. When the water cycle stability in this standalone catchment was broken, the Chotts Megalakes (surface area about $26,000 \mathrm{~km}^{2}$ ) dried rapidly and the strong rain shadow effect of the Atlas Mountain became fully active. Deserts formed immediately in this area and gradually expanded east and south, like a spreading wildfire powered by the prevailing winds (westerlies in winter and trade winds from spring to fall). This led to desertification and aridification in NAWAM synchronously until this day. Therefore, the breach point of the Sahara is the Chotts Megalakes, due to the loss of their enormous water evaporation at the leading position for the westerlies and trade winds.

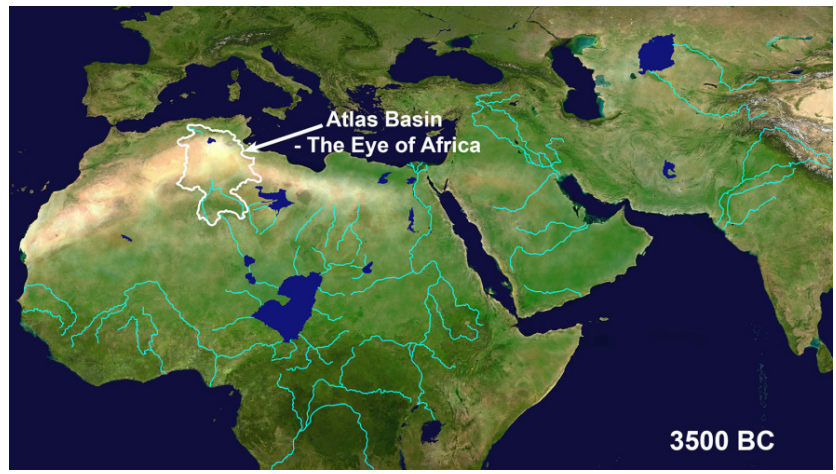

Figure 9 The NAWAM water cycle breach at Chotts Megalakes in Atlas Basin.

The ultimate solution for the MB freshwater imbalance problem is restoration of the green Sahara through remediation of the identified breach. The best way is to use seawater from MS to initialize the balanced water cycle. A short canal may be excavated from the Gulf of Gabes shore toward the west to the highest point of the Gabes ridge, where a large pumping station can be built. To jolt a rapid recovery, a pumping capacity of $2,500 \mathrm{~m}^{3}$ per second (about the current Nile River average flow rate) can be used. With the increase of the water surface area of the Chott Lakes, the air humidity in the southeast area (leeward side) of Atlas Mountains will increase sharply. Precipitation in the Atlas Basin will increase, and the river systems will be rejuvenated. The best water surface area of the Chotts Megalakes is $\sim 30,000 \mathrm{~km}^{2}$ to optimize the green Sahara water cycle. Then, only a small amount of seawater needs to be pumped to maintain the lake water at the optimum level during dry times. During wet seasons, there will be runoff surplus to be released back to MS, which will dilute the salt concentration in the Chotts Megalakes.

\section{Conclusion}

About 1,530 billion $\mathrm{m}^{3} / \mathrm{yr}$ water vapor escapes the Mediterranean Basin (MB), almost 20 times the Nile River annual discharge. This huge water vapor output significantly boosts the precipitation in the nearby areas and amplifies flood intensity, especially in Western and Northern Europe. Freshwater imbalance is not caused by climate change but a result of desertification, deforestation, water diversion to arid places for irrigation, bad agriculture, etc. In fact, the worsening water disparity and desertification are directly responsible for decreasing cloud covers and rising heat waves. The MB freshwater imbalance started at the end of the green Sahara period and has been worsening since then. The Sahara desertification is the only cause for this imbalance. The green Sahara ended when the water cycle stability was broken in the Atlas Basin which is located at the leading edge of the African continent for the westerlies and trade winds. Hence the restoration of the green Sahara is the key to cure the MB freshwater imbalance, and there is a prescription for it.

\section{Acknowledgement}

Thanks to Maggie Zhang for editing. 


\section{Conflicts of interest}

The author declares no conflict of interest.

\section{References}

1. Ballinger TJ, Overland JE, Wang M, et al. Surface Air Temperature. NOAA Arctic Report Card 2020; 2020.

2. Wuebbles DJ, Easterling DR, Hayhoe K, et al. Our globally changing climate. In: Climate Science Special Report: Fourth National Climate Assessment. US Global Change Research Program: Washington, DC USA; 2017. 35-72 p.

3. Rodell M, Famiglietti JS, Wiese DN, et al. Emerging trends in global freshwater availability. Nature. 2018;557(7707):651-659.

4. https://medialibrary.climatecentral.org/resources/downpour-2019

5. Romanou A, Zerefos CS, Clayson CA, et al. Evaporation-precipitation variability over the Mediterranean and the Black Seas from satellite and reanalysis estimates. Journal of Climate. 2010;23(19):5268-5287.

6. Soto-Navarro J, Criado-Aldeanueva F, Garcia-Lafuente J, et al Estimation of the Atlantic inflow through the Strait of Gibraltar from climatological and in situ data. Journal of Geophysical Research. 2010;115(C10):C10023.

7. Maderich V, Ilyin Y, Lemeshko E. Seasonal and interannual variability of the water exchange in the Turkish Straits System estimated by modeling Mediterranean Marine Science. 2015;16(2):444-459.

8. Trenberth KE, Smith L, Qian T, et al. Estimates of the global budget and its annual cycle using observational and model data. Journal of Hydrometeorology. 2007;8(4):758-769.

9. Mariotti A, Struglia MV, Zeng N, et al. The hydrological cycle in the Mediterranean region and implications for the water budget of the Mediterranean Sea. Journal of Climate. 2002;15:1674-1688.

10. Matsoukas C, Banks AC, Pavlakis KG, et al. Seasonal heat budgets of the Red and Black seas. Journal of Geophysical Research. 2007;112(10):C10017.

11. Xue P, Eltahir EAB. Estimation of the heat and water budgets of the Persian Gulf using a regional climate model. Journal of Climate. 2015;28:5041-5062.

12. Zhang HQ. Revive Eden - Green Sahara Now. 2nd ed. Pennsauken, NJ: BookBaby; 2021.

13. Roberts H, Stevenson T, Davis, B. et al., Holocene climate, environment and cultural changes in the circum-Mediterranean region. In: Battarbee, R.W. et al., (ed.) Past Climate Variability through Europe and Africa. The Netherlands: Springer, Dordrecht; 2004. 343-361 p.
14. Combourieu-Nebout N, Peyron O, Bout-Roumazeilles V, et al. Holocene vegetation and climate changes in the central Mediterranean inferred from a high-resolution marine pollen record (Adriatic Sea). Climate of the Past. 2013;9(5):2023-2042.

15. Bar-Matthews M, Ayalon A. Mid-Holocene climate variations revealed by high-resolution speleothem records from Soreq Cave, Israel and their correlation with cultural changes. The Holocene. 2011;21(1):163-171.

16. Marchetto A, Colombaroli D, Tinner W. Diatom response to mid-Holocene climate change in Lago di Massaciuccoli (Tuscany, Italy). J Paleolimnol. 2008;40(1):235-245.

17. Magny $M$, Leuzinger $U$, Bortenschlager $S$, et al. Tripartite climate reversal in Central Europe 5600-5300 years ago. Quaternary Research. 2006;65(1):3-19.

18. Guiot J, Harrison S, Prentice IC. Reconstruction of Holocene precipitation patterns in Europe using pollen and lake-level data. Quaternary Research. 1993;40(2):139-149.

19. Sadori L, Jahns S, Peyron O. Mid-Holocene vegetation history of the central Mediterranean. The Holocene. 2011;21(1):117-129.

20. Di Rita F, Celant A, Magri D. Holocene environmental instability in the wetland north of the Tiber delta (Rome, Italy): sea-lake-man interactions. J Paleolimnol. 2010;44:51-67.

21. Peyron O, Goring S, Dormoy I, et al. Holocene seasonality changes in the central Mediterranean region reconstructed from the pollen sequences of Lake Accesa (Italy) and Tenaghi Philippon (Greece). The Holocene. 2011;21(1):131-146.

22. Vannière B, Power MJ, Roberts $\mathrm{N}$, et al. Circum-Mediterranean fire activity and climate changes during the mid-Holocene environmental transition (8500-2500 cal. BP). The Holocene. 2011;21(1):53-73.

23. Hoerling M, Eischeid J, Perlwitz J, et al. On the increased frequency of Mediterranean drought. Journal of Climate. 2012;25:2146-2161.

24. Philandras CM, Nastos PT, Kapsomenakis J, et al. Long term precipitation trends and variability within the Mediterranean region. Nat Hazards Earth Syst Sci. 2011;11:3235-3250.

25. https://climateknowledgeportal.worldbank.org/

26. McGee D, deMenocal PB, Winckler G, et al. The magnitude, timing and abruptness of changes in North African dust deposition over the last 20,000 yr. Earth and Planetary Science Letters. 2013;371-372:163-176.

27. deMenocal PB, Ortiz J, Guilderson T, et al. Abrupt onset and termination of the African Humid Period: rapid climate responses to gradual insolation forcing. Quaternary Science Reviews. 2000;19:347-361.

28. Zhang HQ. Is Atlantis related to the green Sahara? International Journal of Hydrology. 2021;5(3):132-139. 